\title{
Micro-Mechanical and 3D Fractal Analysis, Durability, and Thermal Behaviour of Nano-Modified Cementitious Lightweight Composites for Building Facades
}

\author{
Marva Angela Blankson ${ }^{1}$, Savaş Erdem ${ }^{2, *}$ and Ezgi Gürbüz ${ }^{2}$ \\ 1 Department of Civil Engineering, University Technology of Jamaica, 237 Kingston, Jamaica; \\ mblankson@utech.edu.jm \\ 2 Department of Civil Engineering, Istanbul University-Cerrahpasa, 34200 Istanbul, Turkey; \\ ezgi.gurbuz@istanbul.edu.tr \\ * Correspondence: savas.erdem@istanbul.edu.tr
}

Citation: Blankson, M.A.; Erdem, S.; Gürbüz, E. Micro-Mechanical and 3D Fractal Analysis, Durability, and

Thermal Behaviour of Nano-Modified Cementitious Lightweight Composites for Building Facades. Buildings 2021, 11, 85. https:// doi.org/10.3390/buildings11030085

Academic Editor: Francisco Almansa

Received: 1 February 2021

Accepted: 22 February 2021

Published: 26 February 2021

Publisher's Note: MDPI stays neutra with regard to jurisdictional claims in published maps and institutional affiliations.

Copyright: (C) 2021 by the authors. Licensee MDPI, Basel, Switzerland. This article is an open access article distributed under the terms and conditions of the Creative Commons Attribution (CC BY) license (https:// creativecommons.org/licenses/by/ $4.0 /)$

\begin{abstract}
There are increasing research endeavours on the application of nanotechnology in the construction industry and lightweight composites. In this study, the influence of different percentage ( $1 \%, 2 \%$, and $3 \%$ by weight of cement) colloidal nano-silica particles on the mechanical, thermal, and durability properties of lightweight cementitious composites was studied through measurement of compressive strength, flexural response, micro-hardness measurement, pore structure analysis, thermal conductivity, water permeability, and chloride penetration. Moreover, 3D X-ray Compute Tomography together with digital image analysis and 3D fractal analysis was used to characterize the nano-silica, micro-structures, and the fracture surfaces. The experimental results show that incorporating nano-silica particles resulted in a mechanical strength increase up to $45.4 \%$ and a water permeability and chloride migration decrease up to $51.2 \%$ and $48.2 \%$, respectively. The micro-structural and 3D fractal analysis also indicated that dense, flaw-free, and thus more resistant, interfaces to micro-cracks were formed and greater fractal dimensions were obtained with the increase of the nano-silica content. Finally, the 3D views confirmed that the nano-silica clusters were well interconnected which further increase the carrying capacity and reducing the heat flow.
\end{abstract}

Keywords: lightweight aggregate; nano-silica; mechanical property; micro-mechanical analysis

\section{Introduction}

Lightweight concrete can be classified in three ways according to its density and the purpose of its use: (I) having a density less than $800 \mathrm{~kg} / \mathrm{m}^{3}$, (II) a target density of $800-1400 \mathrm{~kg} / \mathrm{m}^{3}$ with moderate-strength, and (III) density ranges from $1400 \mathrm{~kg} / \mathrm{m}^{3}$ to $2000 \mathrm{~kg} / \mathrm{m}^{3}$ with structural concrete [1]. In recent years, there has been an increasing demand for use of structural concrete with lightweight aggregates in modern construction methods, thanks to an appreciation of the advantage that a decreased density could result in a decrease in the cross-sections of load-carrying elements and a corresponding reduction in the foundation size [2-4]. In addition, lightweight concrete would be characterized by its lower thermal conductivity compared to normal weight concretes because of the intrinsic porous nature of lightweight aggregates [5]. As a result, lightweight concrete has a huge potential for the use of many modern constructions, for example, lightweight bridge decks [6], lightweight foamed concrete [7], lightweight concrete blocks [8], or thermal isolation constructions [9]. However, lightweight concrete for the same strength level exhibits a quite brittle behaviour compared to conventional concrete as a result of the low fracture toughness, the low tensile-compressive strength ratio, and residual tensile strength [10]. Therefore, a deep understanding of its mechanical behaviour, the interfacial bonding behaviour, energy absorption characteristics, and improvement of its ductility are the key factors to promote its wide acceptance in a variety of structural applications. 
Structure-property relationships in cementitious-based materials are the heart of modern concrete technology. Concrete is highly heterogeneous on multiple scales and has a complex structure made of three distinct constituents at a microscopic scale: aggregates, cement paste matrix, and an interfacial transition zone (ITZ) between these two components. Establishing true structure-property relationships is now one of the greatest challenges for concrete technologists. In parallel, the distinct pore structure having many pores with different sizes has been considered one of the most important characteristics of cementitious materials. The pore structure of the composite controls other important properties including permeability, mechanical properties, dimensional stability, and durability-related properties, and can provide very valuable information regarding both internal structure and structural performance [11,12]. The enhancement of the pore structure is therefore of vital importance for assessing the material behaviour and improving the properties of lightweight concrete.

The approach of nanoparticles as modifiers to improve the engineering properties and performance of concrete is considered promising. One of these nanomaterials is nanosilica which can be used in the form of compacted dry grains and colloidal suspension in mixtures [13]. Previous studies [14-17] have demonstrated that the addition of nano-silica has significantly improved the performance of concrete in terms of mechanical properties, and fracture toughness. Another study [18] has showed that the micro-structure of ITZ and the water permeability resistance capacity of concrete can be significantly enhanced with the addition of nano- $\mathrm{SiO}_{2}$. In general, the improvement of the performance of cementitious composites with the addition of nano-silica can be attributed to the fact that the nano-silica particles fill the voids between the cement grains resulting in much denser the microstructure and act as nucleating centers for the chemical generation of cement hydrates [19].

While knowledge regarding the effects of nano-silica modification on the cementitious composites with normal weight aggregates is widely established, only limited studies (especially with low dosage modification) are available in the literature. A considerable improvement in both early-age and late-age compressive and flexural tensile strengths has been reported in a recent study by Zhang et al. [20]. They studied the effect of a low dosage of nano-silica addition ( 0.1 to $1 \%$ by weight) on the lightweight aggregate concrete. However, the authors reported that the nano-silica modified specimens exhibited similar strengths compared with the corresponding control specimen when exceeding the optimal dosage which is called the neutralization effects of nano-particles. In another experimental study, Wang et al. [21] investigated the influence of nano-silica $(1 \%, 2 \%$, and $3 \%$ ) addition on the static strength, shrinkage behaviour, and resistance to early-age cracking of the concrete. The improvement of the compressive strength of the lightweight aggregate concrete noticeably occurred at early ages (within 28 days). In terms of microstructure modifications, the interfacial transition zone between the lightweight aggregate and surrounded cement matrix was much denser and more continuous compared to the lightweight mix without nano-silica. Moreover, with the incorporation of the nanosilica, the long-term shrinkage of the lightweight concrete did not seem to be affected significantly, while the total cracking area (as a reflection of the early cracking sensitivity) of the lightweight mixes showed a continuous decrease with the addition of nano-silica particles. A wide range $(1,2,5$, and $10 \mathrm{wt}$. \%.) dosage of nano-silica was evaluated in the work of Sikora et al. [22]. They characterized the effects of nanosilica on the properties of lightweight aggregate concrete referring to an oven-dry density of $850 \mathrm{~kg} / \mathrm{m}^{3}$ and ultralightweight aggregate concrete referring to an oven-dry density of $450 \mathrm{~kg} / \mathrm{m}^{3}$, respectively. They observed considerable improvements for the mechanical and transport properties and a better efficiency than that of silica fume. Moreover, the 3D micro-structural analysis conducted by a micro-computed tomography also confirmed the production of a very dense void structure and the pore refinement contributing to a less permeable cement matrix.

In contrast to the studies mentioned above, Vargas et al. [16] were evaluated the influence of the replacement of a high dosage of nano-silica (10 wt. \%) on the performance of the lightweight aggregate concrete. They found that the characteristics of lightweight 
aggregates used in the manufacturing of lightweight concrete are the main parameters to control its compressive strength and durability performance. However, the nano-silica had a considerable effect on refinement of the pore structure resulting in a lower volume of voids and a decreased water absorption rate and thus, improved durability performance. Furthermore, a study [20] about the effect of colloidal nano-silica on lightweight concrete shows that relatively high dosage of nano-silica will create the internal stress resulting from the production of hydration product at the boundary of the lightweight aggregates and the surrounded cement matrix which, in turn, decreases the modification of the nano-particles.

The literature review above clearly indicates that research in this field has mainly focused on the evaluation of mechanical properties, durability behaviour, and thermal performance at a macro level. However, research conducted so far is still less to evaluate comprehensively the microstructure associated mechanical and durability characterization of lightweight cementitious mixes modified with nano-silica, as well as 3D fractal cracking characterization. In addition, the potential structural application of this type of cementitious composites has been paid less attention. This leads to the aim of this study, which is to analyze the micro-structural damage characteristics of nano-modified lightweight cementitious composites that have experienced mechanical, thermal, and chemical effects, so as to assess the influence of the low dosage addition of the nano-particles. A complementary objective is to make a comparison between the mechanical, thermal, durability, and bond behaviour of composite and its micro-structure as exemplified in mixes produced with sintered fly ash lightweight aggregates with and without nano-silica addition. This will be addressed via testing the mechanical properties (compressive strength, and flexural tensile strength), as well as the microstructural and crack analysis via; scanning electron microscopy, micro-hardness analysis, $\mathrm{X}$-ray diffraction, mercury porosimetry analysis, energy dispersive $\mathrm{X}$-ray analysis (EDX), and fractal analysis.

\section{Experimental Program}

\subsection{Materials Used and Concrete Mixtures}

Portland Cement CEM I 52.5N, coarse lightweight aggregates, local fine sand having a specific gravity of 2.66 , and a polycarboxylate ether-based superplasticizer, provided by BASF, Germany, were used to make the mixtures. The lightweight coarse aggregate used in this study was sintered fly ash produced by pelletizing the fly ash at a temperature of around $1100{ }^{\circ} \mathrm{C}$. As a result of this process, the aggregates had a rounded shape. The X-ray Diffraction (XRD) technique was used to analyze the mineralogy patterns of the aggregates and the analysis results are illustrated in Figure 1. The lightweight aggregates with a nominal maximum size of $10 \mathrm{~mm}$ had a specific gravity $1.35 \mathrm{~g} / \mathrm{cm}^{3}$ and water absorption of 27.2 as \% of dry mass.

The XRD analysis demonstrated that the fly ash aggregate used would have significant amorphous content. The hump in the pattern would indicate that the amorphous phase is most likely silica having pozzolanic characteristics [23]. Nano-silica (Figure 2) has been selected in colloidal form (Figure 2) in order to provide a homogenous distribution of the nano-silica in the matrix and decrease the risk of nano-particles agglomeration [24]. Nano-silica used in this experimental work (50 wt. \% of solid mass) has been provided by EKA Chemicals. The nano-particles with a particle size in the range of 5-20 nm have a density of $1.3 \mathrm{~g} / \mathrm{cm}^{3}$ and a $\mathrm{pH}$ value of 9.4 . 


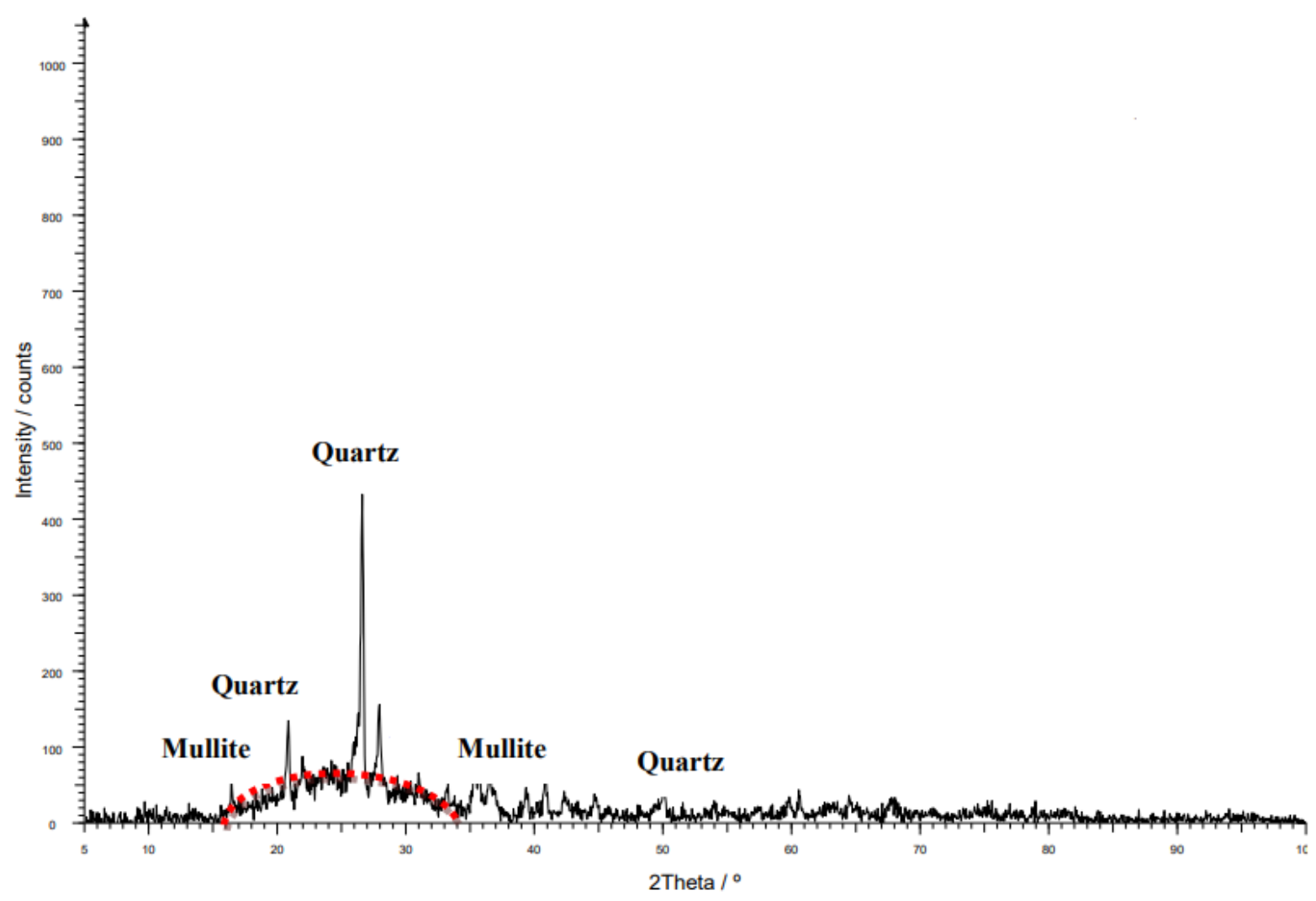

Figure 1. XRD pattern of the lightweight fly ash aggregate.

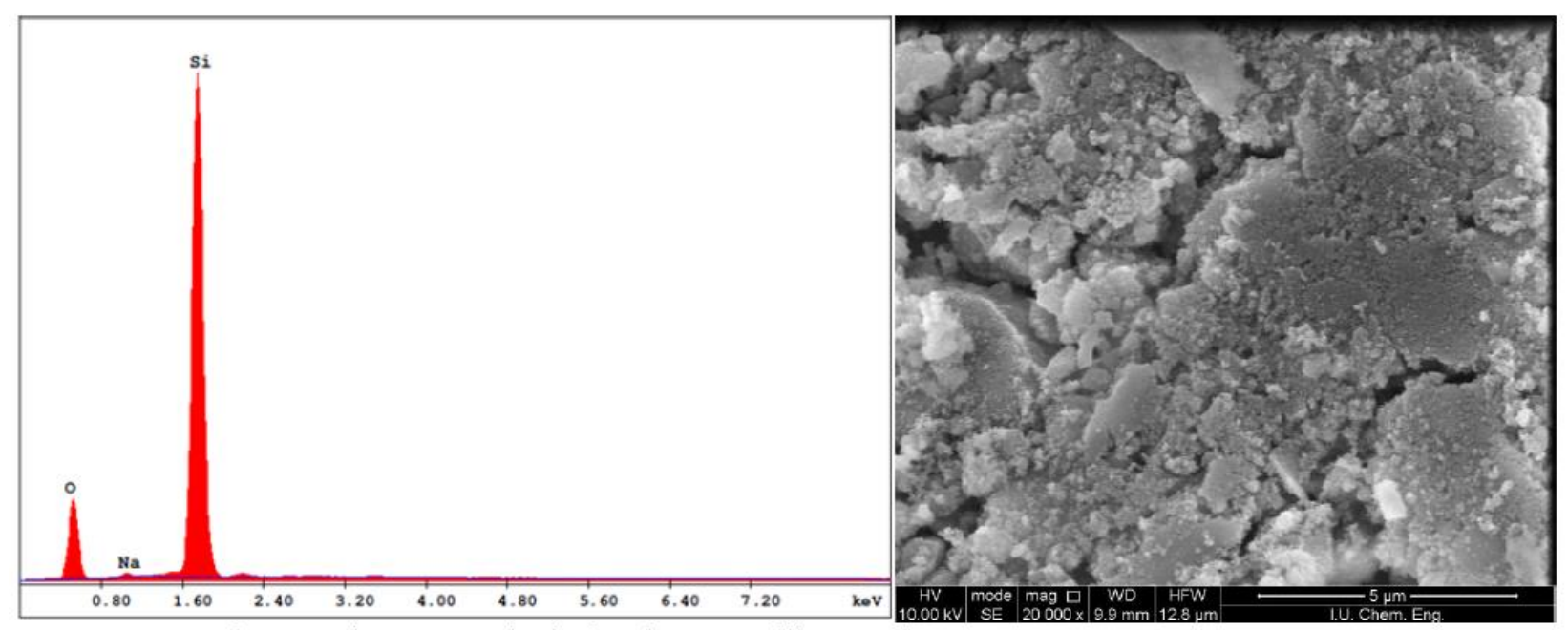

Figure 2. SEM photo and analysis for the nano silica particles.

\subsection{Production of Concrete Mixtures}

The volume method is preferred for the design of the concrete mixtures, and the mix proportions are illustrated in Table 1 . The $\mathrm{w} / \mathrm{c}$ ratio was the same as 0.35 for the mixtures, and the different dosages of the nano-particles ( $1 \%, 2 \%$, and $3 \%$ by weight of cement) were used for manufacturing concrete mixes. Considering the relatively high cost of nanoparticles and the literature review (very limited studies to investigate the nano-modification effects on the lightweight cementitious mixes), low replacement ratios were chosen. Four different mixes with/without the nano-particles were cast and tested, namely control concrete containing lightweight coarse without nano-silica (RC), lightweight aggregate 
concrete with $1 \%$ nano-silica (LAC-1), lightweight aggregate concrete with $2 \%$ nano-silica (LAC-2), and lightweight aggregate concrete with 3\% nano-silica (LAC-3).

Table 1. Mix proportions for $1 \mathrm{~m}^{3}$.

\begin{tabular}{ccccccc}
\hline Mixture & $\begin{array}{c}\text { Cement } \\
(\mathbf{k g})\end{array}$ & $\begin{array}{c}\text { Water } \\
(\mathbf{k g})\end{array}$ & $\begin{array}{c}\text { Fine } \\
\text { Aggregate } \\
\mathbf{( k g )}\end{array}$ & $\begin{array}{c}\text { Lightweight } \\
\text { Coarse } \\
\text { Aggregate } \mathbf{( k g )}\end{array}$ & $\begin{array}{c}\text { Nano-Silica } \\
(\mathbf{k g})\end{array}$ & $\begin{array}{c}\text { Density } \\
\left(\mathbf{k g} / \mathbf{m}^{\mathbf{3}}\right)\end{array}$ \\
\hline RC & 500 & 175 & 566 & 554 & - & 1645 \\
LAC-1 & 495 & 175 & 566 & 554 & 10 & 1633 \\
LAC-2 & 490 & 175 & 566 & 554 & 20 & 1622 \\
LAC-3 & 485 & 175 & 566 & 554 & 30 & 1664 \\
\hline
\end{tabular}

The fly ash lightweight aggregates have been used in the saturated surface dry condition. For that purpose, the lightweight aggregates were immersed in water for a period of 24 to provide fully saturated particles. Then, the lightweight aggregates were spread on a pan and exposed to air-dry conditions for $24 \mathrm{~h}$ in which the lightweight aggregates absorb no water during the mixing process [25]. The fresh concrete was placed into the moulds in two layers and then vibration was applied to remove entrapped air bubbles as well as levels the fresh concrete. Finally, the de-molded specimens were cured in the environment of $20 \pm 2{ }^{\circ} \mathrm{C}$ and $65 \%$ relative humidity.

\subsection{Tests Conducted}

Three cubes $(100 \mathrm{~mm})$ specimens for the compressive strength of each mixture were tested at the age of 7,28, and 56 days based on TS-EN 12390-3 [26]. The ultrasonic pulse velocity of cube specimens was performed using a PUNDIT equipment (portable ultrasonic non-destructive digital indicating tester). $100 \times 100 \times 400 \mathrm{~mm}$ of prism specimens were tested to determine the flexural tensile strengths of the mixes at the age of 7,28 , and 56 days. An open access ImageJ software was then employed to characterize the flexural load-induced fracture surfaces and compute the fractal dimensions of the mixtures were calculated. Then, the fracture energies of the concretes were estimated as a function of the surface macro-cracks by the following Formula 1 [27]:

$$
\mathrm{Ws} / \mathrm{Gf}=\mathrm{a} \times(\delta / \mathrm{a})^{\mathrm{D} 1-\mathrm{d}}
$$

where $a$ is the height of the cross-section of the tested sample, $\delta$ is the maximum size of the fine particle, and $D^{1-d}$ is the fractal dimension of the fracture surface or a crack, respectively.

A Vickers micro-hardness test was performed to measure the micro-hardness of the ITZs. A load of $0.01 \mathrm{~kg}$ with 10 s contact time has been applied to the region of $100 \mu \mathrm{m}$ away from the surface of aggregates. The chloride migration test was performed according to the NT BUILD 492 [28] procedure. A silver nitrite indicator solution (Figure 3) was used to measure the chloride migration depths of $100 \times 50 \mathrm{~mm}$ cylinder specimens and the non-steady-state migration coefficients (Dnssm) were computed based on the formulas reported by Luo and Schutter [29]. The water penetration tests were conducted according to TS-EN 12390-8 [30] at the age of 28 days. For that purpose, one side of $150 \mathrm{~mm}$ cube specimens was exposed to water for a pressure of $500 \pm 50 \mathrm{kPa}$ for 72 hours. The specimens were then split into two halves by using the compressive test set-up. At the final stage, the water penetration sections on the lightweight cement composite surface were highlighted and the maximum depth of the penetration of the water in specimens was recorded. 


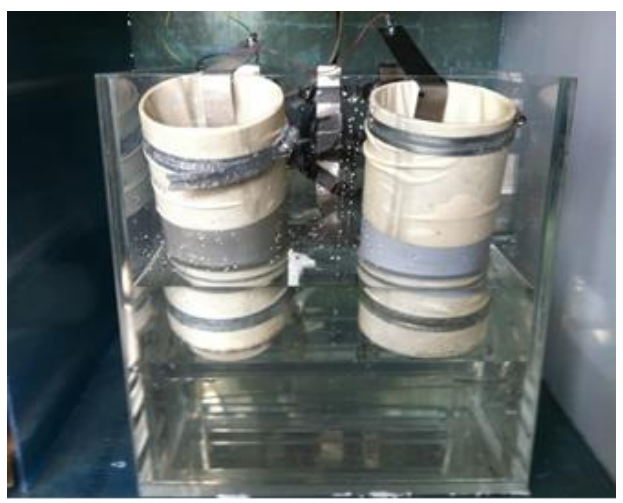

Figure 3. Chloride migration test set up.

A C-Therm/ Tci thermal conductivity equipment was used to measure thermal conductivity coefficients $(\mathrm{k})$ of the sample parts which were used for compressive strength test. The measurement has been done according to ASTM Standard E1952 [31] with five replicated specimens.

In this study, a mercury intrusion porosimetry device was also used to characterize the pore structure of the lightweight mixes. The relationship between the applied pressure and the volume of intruded mercury was quantitatively observed for each lightweight mix.

Pull-out tests were also carried out to assess, to some extent, the performance of this nano-modified lightweight cementitious composites in structural applications. For that purpose, the reinforcing ribbed steel-bar of $14 \mathrm{~mm}$ diameter was extracted from the lightweight cementitious composites cube specimens with a size of $150 \times 150 \times 150 \mathrm{~mm}$ at the age of 28 days (Figure 4). A controlled displacement test according to ASTM E151201 [32] was carried out at a fixed displacement rate of $0.5 \mathrm{~mm} / \mathrm{min}$, and the reactive load was recorded and then, the bond stress was calculated using by Formula 2.

Calculation of bond stress,

$$
\tau=\text { Applied Force } / \pi \phi 1
$$

where;

$$
\begin{aligned}
& \tau=\text { Bond stress }\left(\mathrm{N} / \mathrm{mm}^{2}\right) \\
& \phi=\text { Reinforcement bar diameter }(\mathrm{mm}) \\
& 1=\text { Anchorage length }-\mathrm{mm} \text { (length of reinforcement embedded in concrete) }
\end{aligned}
$$
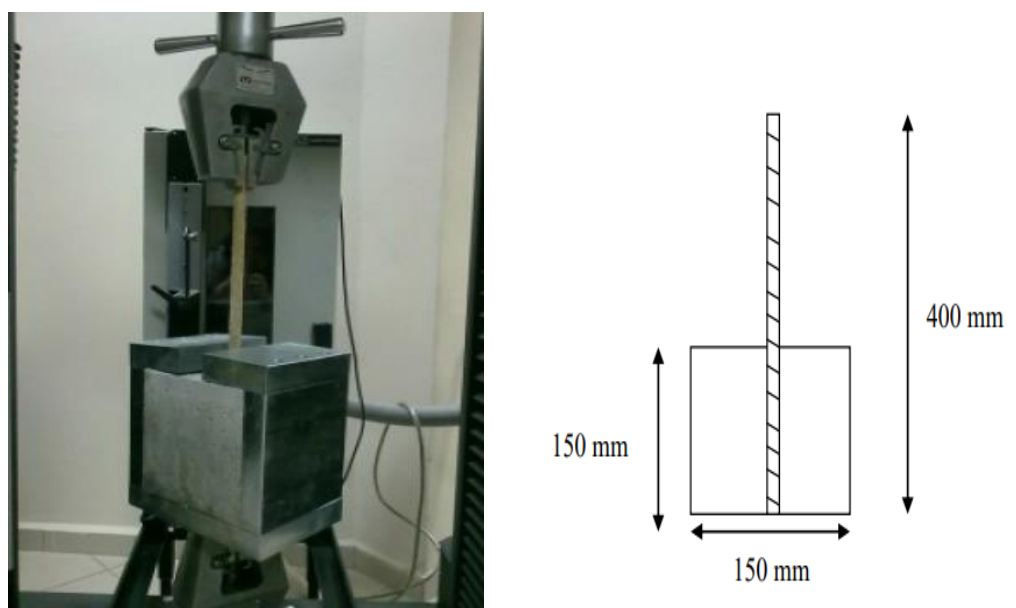

Figure 4. Pull-out test set up. 


\section{Results and Discussions}

\subsection{Micro-Structure Associated Compressive Strength}

Compressive strength test results of the lightweight and nano-modified lightweight mixtures at 7, 28, and 56 days are illustrated in Figure 5. The results, in general, indicate an increasing trend of the compressive strength when the nano-silica was incorporated into the mixes.

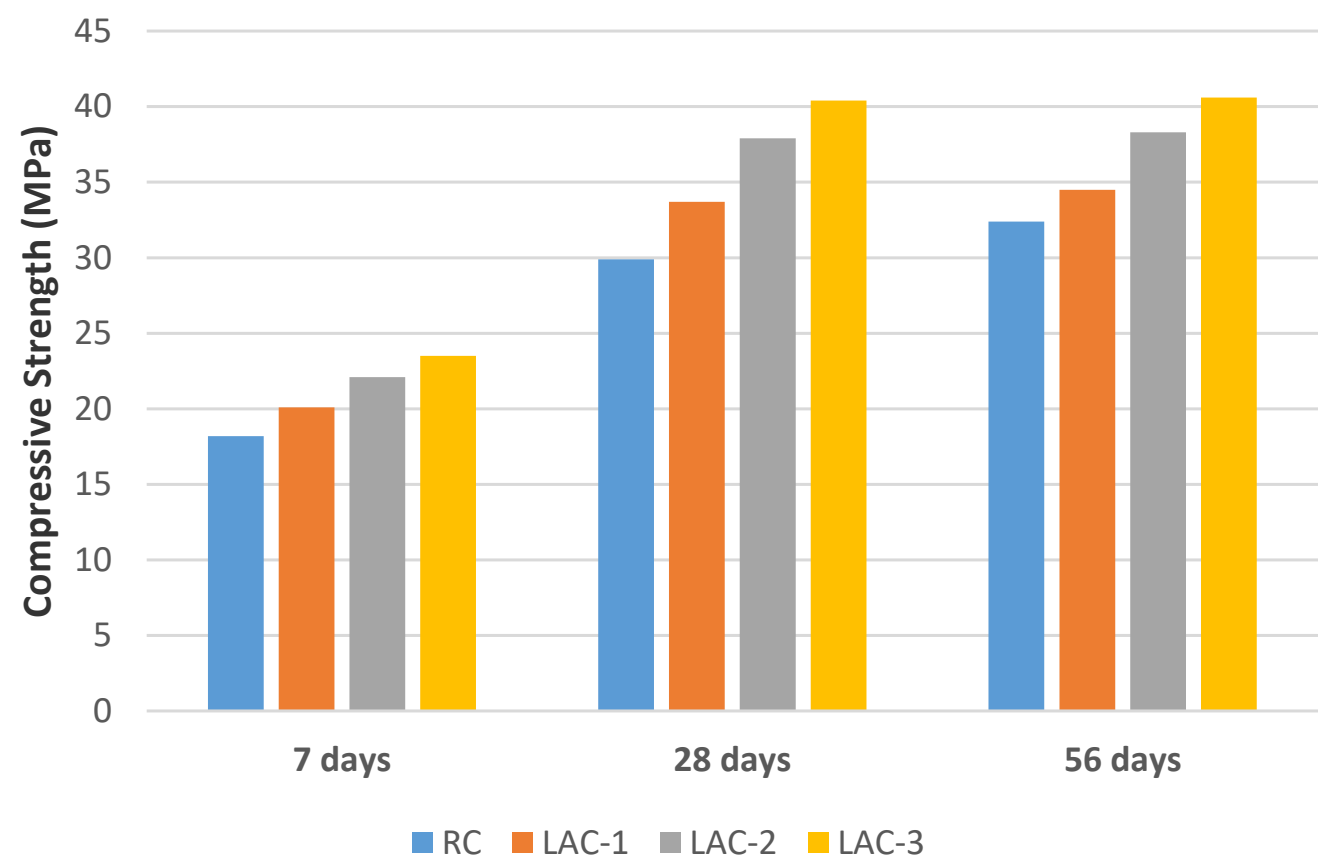

Figure 5. The compressive strength test results of the mixes.

Compared to the reference mix, the 28 days compressive strength improvement ratios of the samples including nano-silica particles with the proportions of $1 \%, 2 \%$, and $3 \%$ by weight of cement were $12.70 \%, 26.8 \%$, and $35.1 \%$, respectively. This confirms that an increase in the rate of nano-silica particles in the lightweight mix resulted in the enhancement in the compressive strength. By adding the nanoparticles, the bond between the lightweight aggregate particles and the matrix was improved as a result of the advanced hydration degree. This is mainly credited to the high degree of pozzolanic reaction in the nano-silica modified lightweight system. The distinct hump shown by a red dash line in the XRD analysis in Figure 2 indicates that the presence of considerable amounts of amorphous silica material and the pozzolanic characteristic. The significant amorphous silica content of the particles reacted with calcium hydroxide and fill the pores existing in the matrix with C-S-H gels (Figure 6). The mercury porosimetry test result presented in Section 3.3 also provides good support for this theory and indicates that the percentage of pore volume in the nano-modified lightweight mixes was significantly lower than the reference mix. Following that, the increased integrity of the concrete matrix may improve the connected area and carrying capacity for the matrix materials that flow and deform around the lightweight aggregate against the compressive loading. 

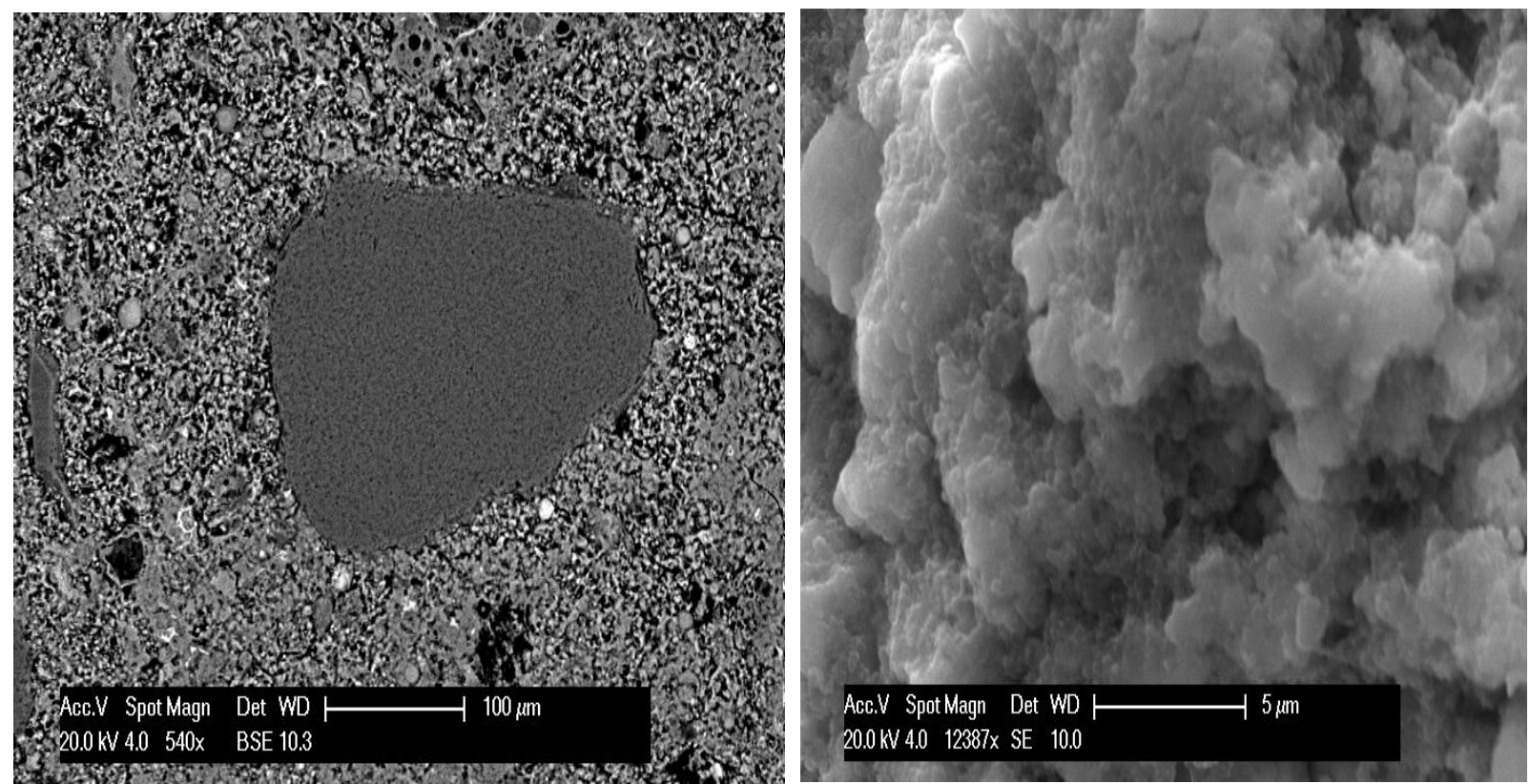

Figure 6. Scanning electron microscope views of the micro-structure.

Figure 7 illustrates the relationship between the average micro-hardness (strength) distribution measured in the interfacial transition zone of each lightweight mix and the distance from the aggregate surface. The results clearly show that there are noticeable differences between the specimen behaviors. In the mix encompassing 3\% nano-silica particles, the micro-hardness at the distance of $50 \mu \mathrm{m}$ away from the sintered fly ash aggregate surface reached a level of $38 \mathrm{HV} \mathrm{0.01,} \mathrm{while} \mathrm{it} \mathrm{was} \mathrm{only} 29 \mathrm{HV} 0.01$ for the reference mix which does not contain any nano-particles.

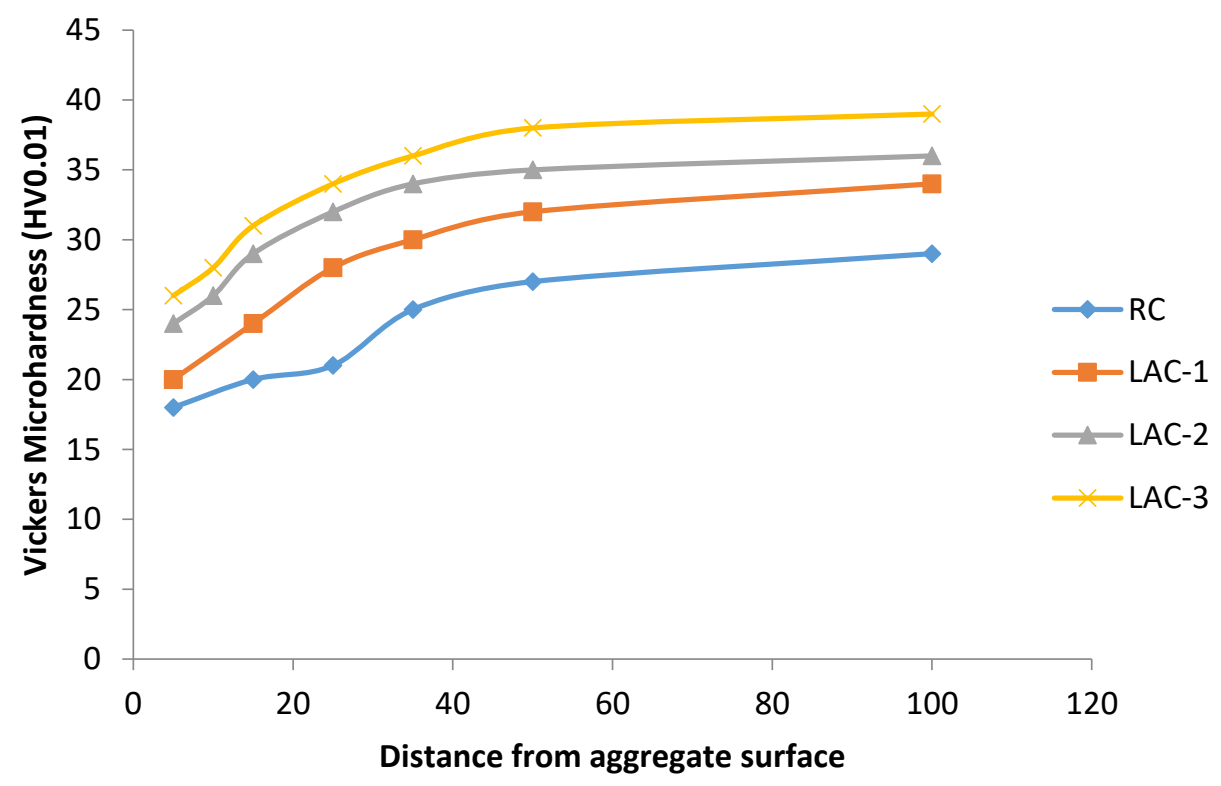

Figure 7. Micro-hardness values of the ITZs of the mixes.

As previously stated by Erdem [33] and Perkins [34], the greater the crystallinity the stiffer the composites, or the higher the strength. From a microstructural and chemical science point of view, adding nano-silica particles into the lightweight mixes would increase the crystallinity of the mixes which, in turn, resulted in a higher micro-hardness value compared to the reference mix. This is mainly credited to a higher crystallinite 
proportion of the nano-silica (as confirmed in Figure 2) as a result of a significant number of unsaturated bonds.

In parallel, the 3D micro-computed tomography views of the mix with nano-silica particles have also supported this theory to some extent. It can be seen from Figure 8 that the inclusion of the nano-silica particles into the lightweight mix led to densification and homogeneity of the interfacial matrix and provided superior bonding. In addition, the colloidal nano-silica particles were distributed in a very homogeneous way in the matrix, which indicates that dense, flaw-free, and thus more resistant interfaces to micro-cracks were formed with the increase of the nano-silica content.
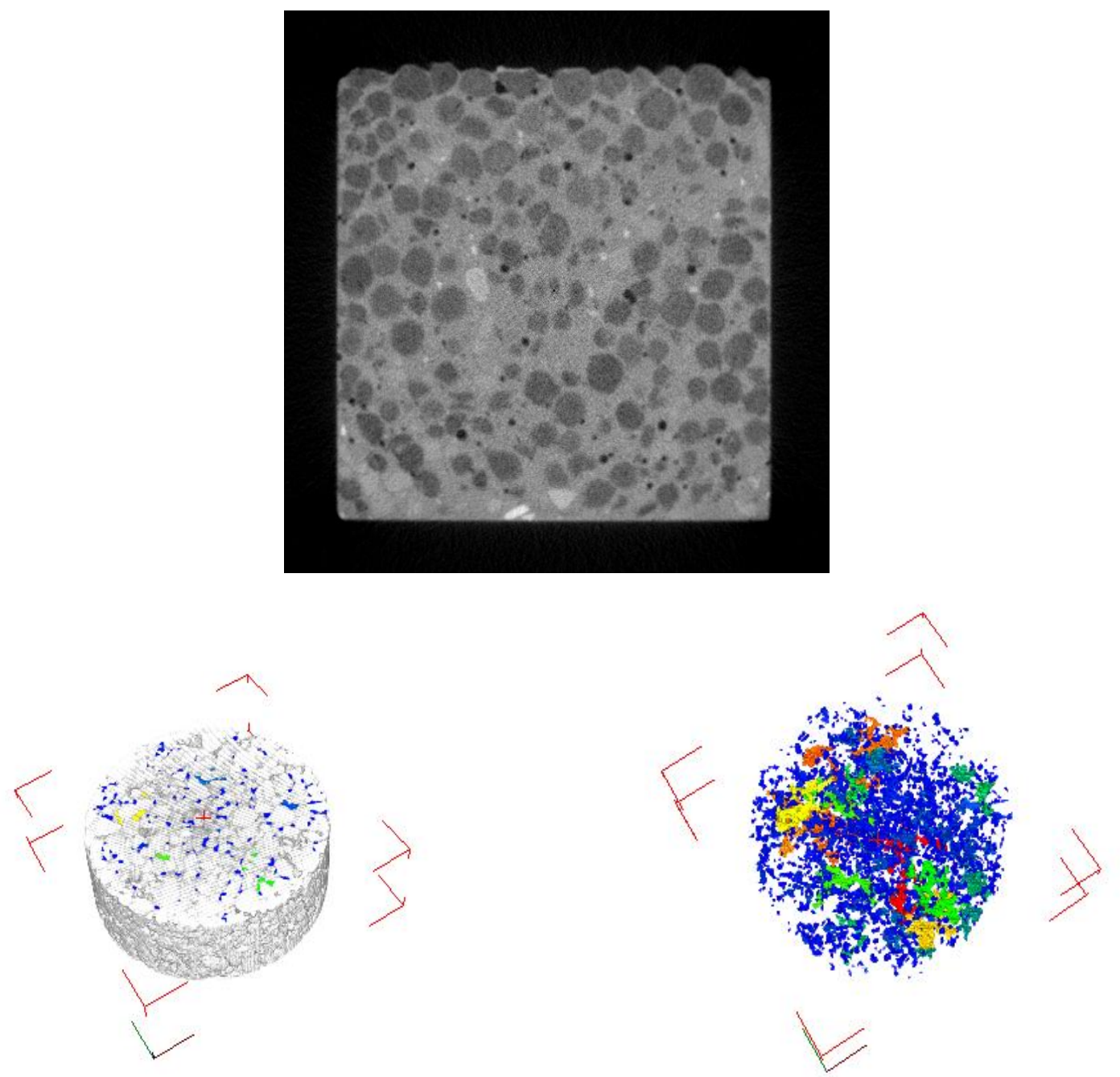

Figure 8. 3D X-ray micro-tomography views of the nano-silica modification.

\subsection{Flexural Strength and $3 D$ Crack Analysis}

In general, the flexural strength of the lightweight mix increases in parallel with the increase in the percentage of nano-silica particles (Figure 9). The results, in general, indicate an increasing trend of the flexural tensile strength when the nano-silica particles were incorporated into the mixes. 


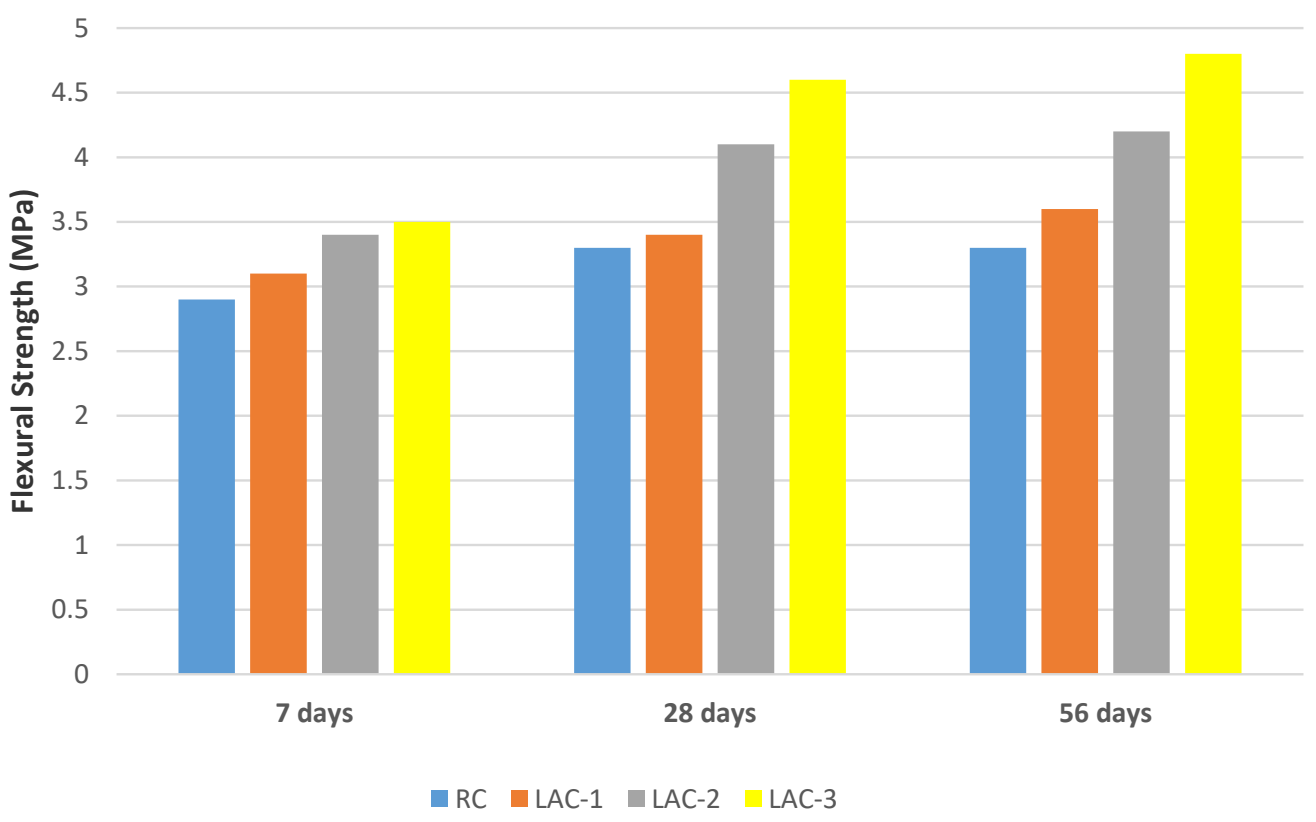

Figure 9. The flexural strength test results of the mixes.

Compared to the reference mix, the 56 days flexural tensile strength improvement ratios of the samples including nano-silica particles with the proportions of $1 \%, 2 \%$, and $3 \%$ by weight of cement were $9.90 \%, 27.7 \%$, and $45.4 \%$, respectively. With the aggregate in the four lightweight mixes being the same, it would be deduced that the higher level of tensile stresses occurred in the interfacial transition zone between the aggregate and the surrounded matrix. The stronger ITZ (as confirmed by the micro-hardness results) in the mix reinforced with nano-particles could efficiently contribute to the stress transfer mechanism which, in turn, results in greater flexural strength.

After the flexural tensile strength tests of 28-day samples, the fractal analysis has been conducted on fractured specimens of the lightweight mixes. Then, the fractal dimensions of the surface cracks were computed for each mix. Although various methods (cube counting, variance methods, etc.) are available in the literature for calculating the fractal size, the most practical and used method is box counting, which is based on measuring the boundaries of a shape using by the lengths between points on it considering square boxes. The details of the methods were discussed in a previous study by Erdem and Blankson [35]. Following that, the fracture energy (Ws/Gf) of the samples in $\mathrm{mm}$ was calculated at the macro level using the formulation proposed by Guo et al. [27]. The value of Ws/Gf indicates the ratio of the total energy (Ws), which is released during crack propagation, to the fracture energy (Gf).

The fractal size values of the fracture surfaces obtained by Image J program are illustrated in Figure 10. The results clearly show that the lightweight mix with a percentage of $3 \%$ nano-silica particles (LAC-3) has the highest fractal dimension value among the mixes. In addition, the other nano-silica reinforced lightweight samples had also a fractal dimension greater than the reference lightweight mix (RC). The higher fractal dimension of the LAC-3 mix led to the dissipation of a higher fracture energy at the macro scale level as confirmed by the results presented in Table 2. The higher fractal dimension values associated with the addition of nano-silica particles revealed that the unsaturated bonds significantly reduced the hydrophobicity and static contact angle for the nano-silica improving the bond ability between them and hydration products and producing the toughening mechanism along the crack front and voids. 

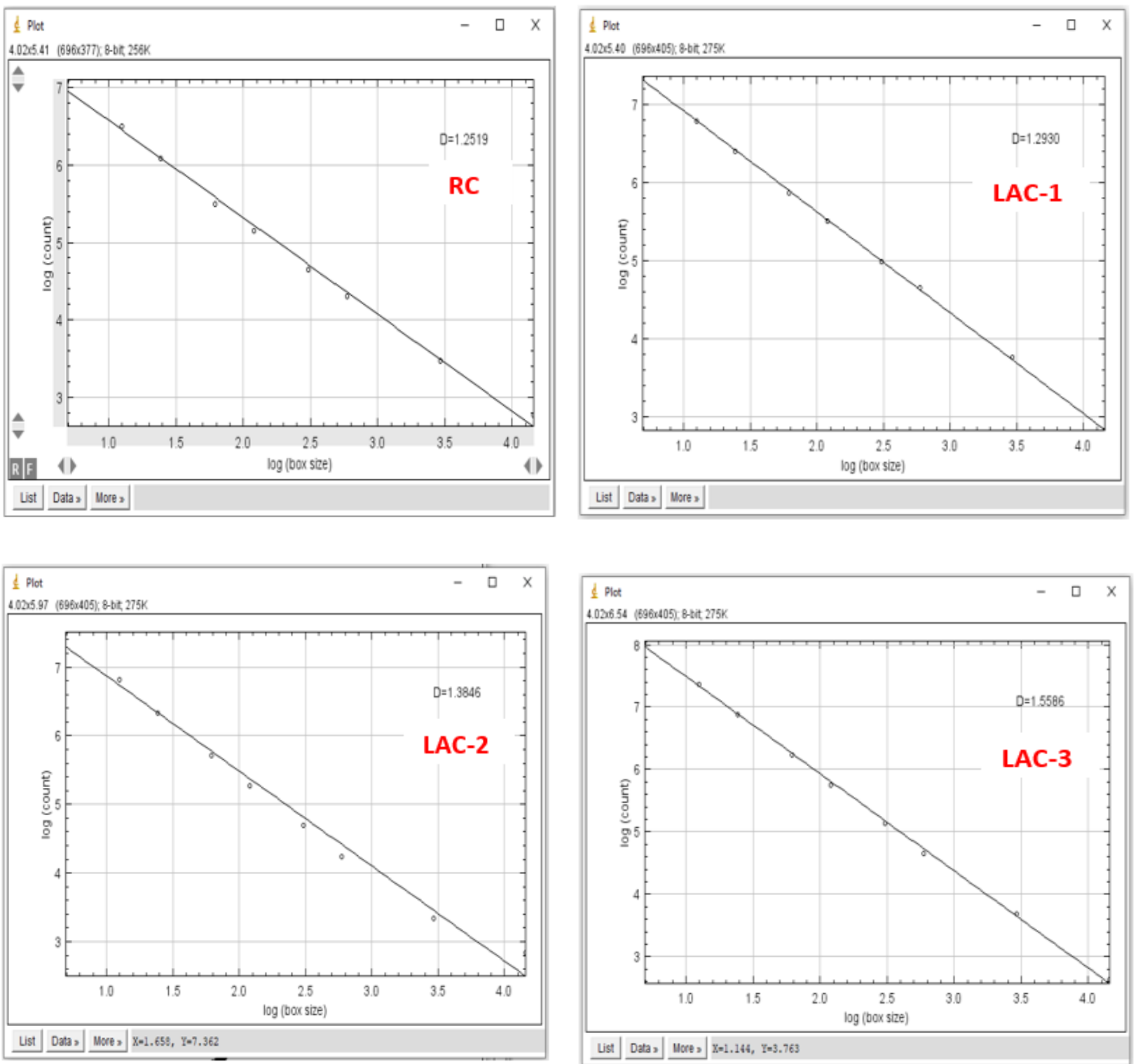

Figure 10. Fractal dimensions of the mixes.

Table 2. Fractal dimensions vs. Ws/Gf values.

\begin{tabular}{ccc}
\hline Mix ID & Fractal Dimension -D & Ws/Gf (mm) \\
\hline RC & 1.2519 & 71.44 \\
\hline LAC-1 & 1.2930 & 78.53 \\
\hline LAC-2 & 1.3846 & 96.98 \\
\hline LAC-3 & 1.5586 & 144.76 \\
\hline
\end{tabular}

Three-dimensional images of the fractured surface roughness of the samples are illustrated in Figure 11. According to the above-mentioned results, the sample with 3\% nano-silica particles gave the highest energy value during crack occurring and propagation. Figure 11 shows 3D dimensional surface curves of the mixes associated with the depths of the points of the samples. The results revealed the crack width and depth at the LAC-3 was high, and at the same time, the cracks spread reached to the upper fibers with a much larger surface area leading to the greater fracture energy. 

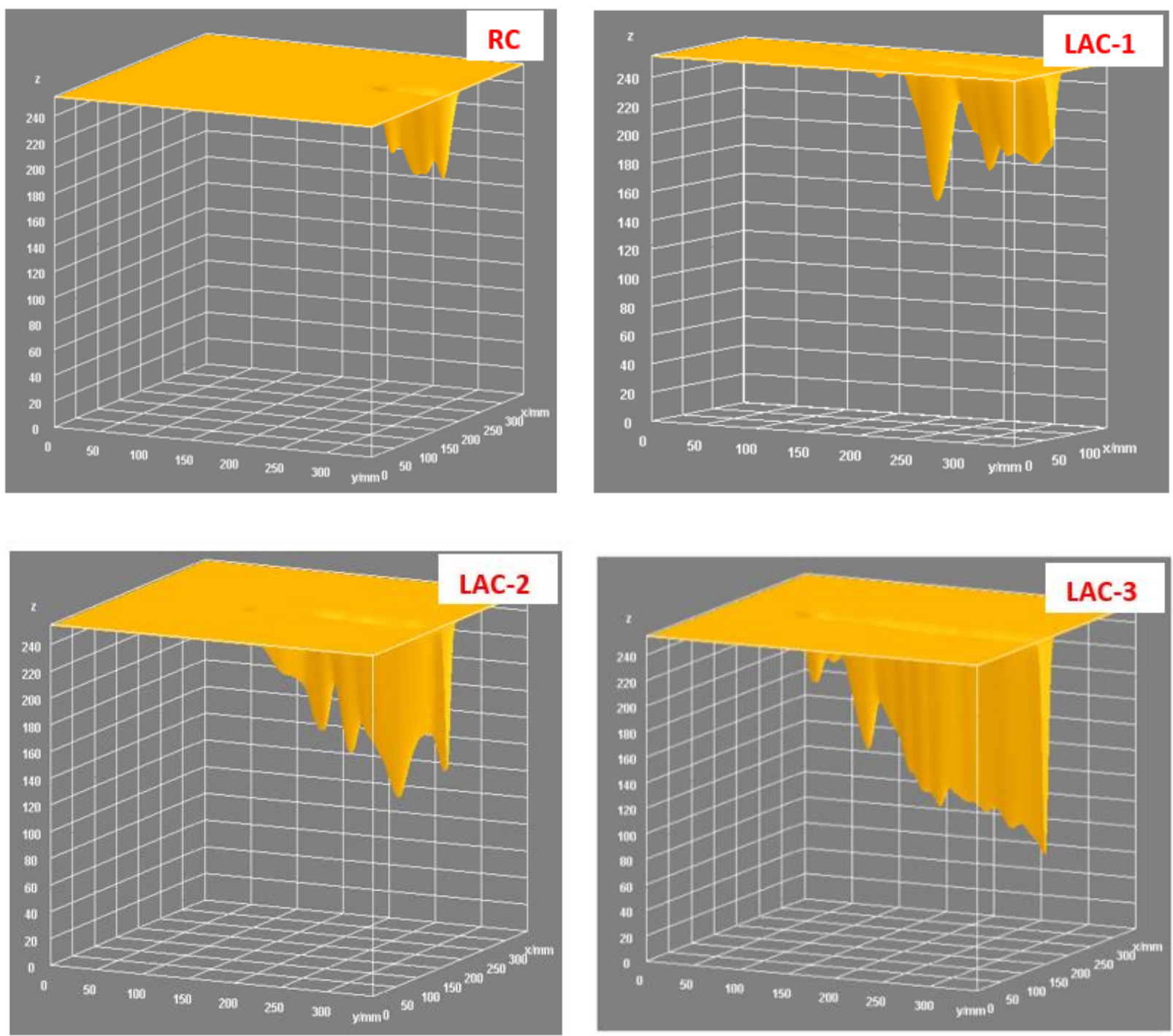

Figure 11. 3D surface plots of the fracture surfaces of the mixes.

\subsection{Water Permeability and Chloride Migration}

In the four types of lightweight cementitious composites, the transport properties were also studied in order to understand the durability behaviour. It is very well-known that one of the degradations mechanisms of the cementitious composites is sourced from the aggressive media such as sulphate and chloride riches environments in which the chemicals penetrate the concrete matrix through the voids. The water permeability and the non-steady state chloride migration tests would therefore provide good indicators of the durability of the composite [36].

Table 3 illustrates the average results after these two durability tests were conducted on the representative lightweight and nano-silica modified lightweight samples. At 28 days, the depth of water penetration was $51.2 \%$ higher in the lightweight mix (RC) than that with $3 \%$ nano-silica particles (LAC-3). It is also shown that, in comparison to the reference mix (RC), the computed chloride migration coefficient from non-steady state migration $\left(D_{n s s m}\right)$ at 28 days was $48.22 \%$ higher than in the lightweight cementitious composites modified with $3 \%$ nano-silica particles. 
Table 3. Water permeability and chloride penetrability test.

\begin{tabular}{ccccc}
\hline Mix ID & $\begin{array}{c}\text { Water Permeability } \\
(\mathbf{m m})\end{array}$ & $\begin{array}{c}\text { Chloride } \\
\text { Penetration }\end{array}$ & & \\
\hline & & $\mathbf{D}_{\text {nssm }} \times \mathbf{1 0}^{-\mathbf{1 2}}$ & $\begin{array}{c}\text { Charge Passed } \\
\text { (Coulombs) }\end{array}$ \\
\hline RC & 37 & 12 & 12.4 & 2678 \\
\hline LAC-1 & 32 & 9 & 9.56 & 1989 \\
\hline LAC-2 & 26 & 7 & 7.12 & 1892 \\
\hline LAC-3 & 18 & 6 & 6.42 & 1746 \\
\hline
\end{tabular}

According to the evaluation criteria by NT BUILD 492 [28], all the nano-modified lightweight cementitious mixes can be described as having high resistance to chloride penetration, whereas the reference lightweight mix can be classified as having medium resistance to chloride ion penetration. In addition, in this test, the higher $\mathrm{D}_{\text {nssm }}$ measurement shows that any steel reinforcement that is placed in the lightweight cementitious mixes without nanoparticles would be more susceptible to corrosion. While other features may have helped to reduce the transport property of the lightweight cementitious mixes with nano-silica modification, it is plausible that a refinement of pore structure (the volume of micro pores is $65 \%$ bigger [26]) with the addition of the colloidal nano-silica particles has occurred as shown in Table 4 and Figure 12. The pore refinement would provide the stronger interfacial transition zone which makes the difficult the movement of the chemical substances or water across its length.

Table 4. The calculated percentage of the micro and macro pores.

\begin{tabular}{ccc}
\hline Mix ID & Micro Pores (\%) & Macro Pores (\%) \\
\hline RC & 68.40 & 31.6 \\
\hline LAC-1 & 72.30 & 27.7 \\
\hline LAC-2 & 77.40 & 22.6 \\
\hline LAC-3 & 81.10 & 18.9 \\
\hline
\end{tabular}

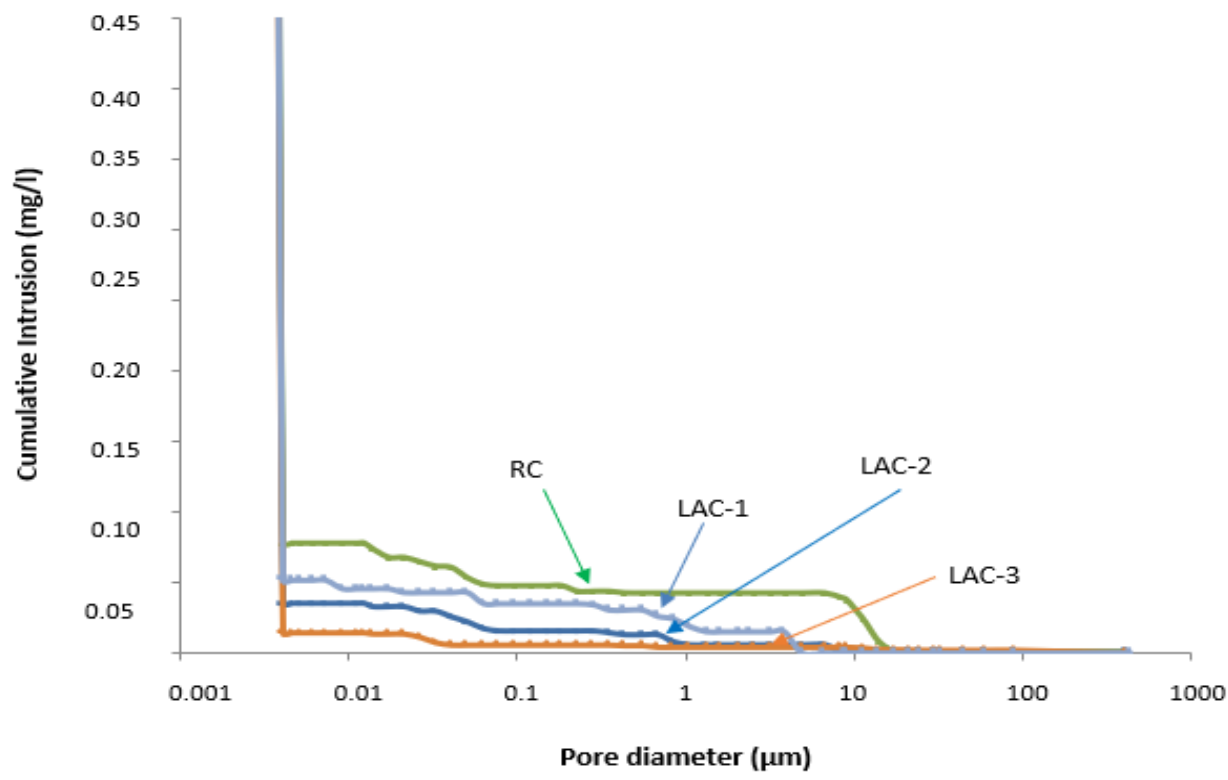

Figure 12. The pore structure analysis of the mixes. 


\subsection{Thermal Conductivity}

Figure 13 represents the results of thermal conductivity of the lightweight cementitious composite specimens. Figure 14 shows an inverse relationship between the microstructural homogeneity (as measured by the ultrasonic pulse velocity measurements) and the thermal conductivity for the lightweight mixes. There were no significant differences between the specimens in terms of the measured thermal conductivity values, and all the lightweight specimens tested exhibited relatively low thermal conductivity values (lower than $0.55 \mathrm{Wm} / \mathrm{K})$.

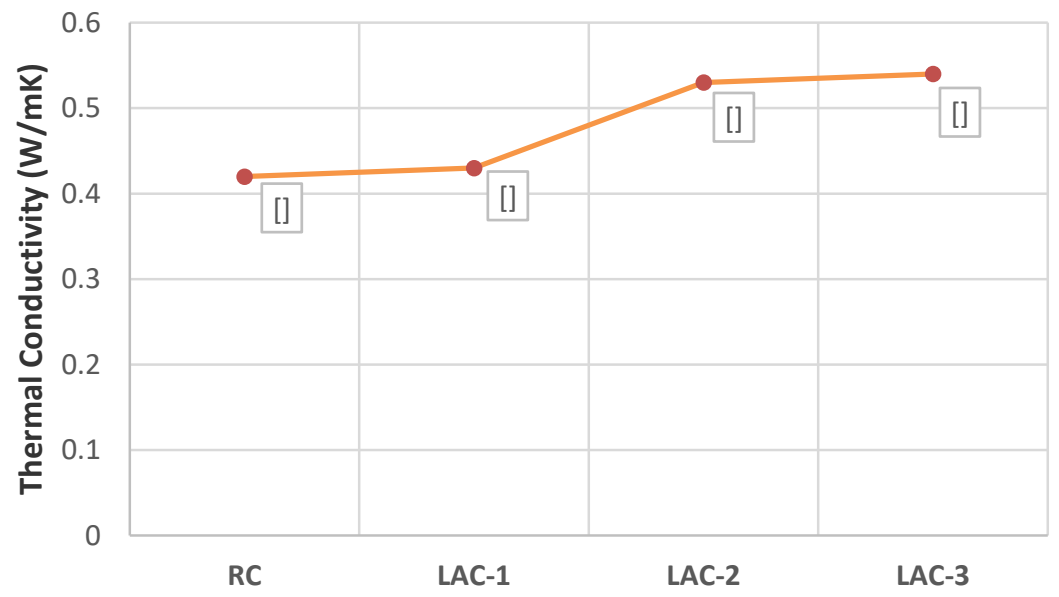

Figure 13. Thermal conductivity of the mixes.

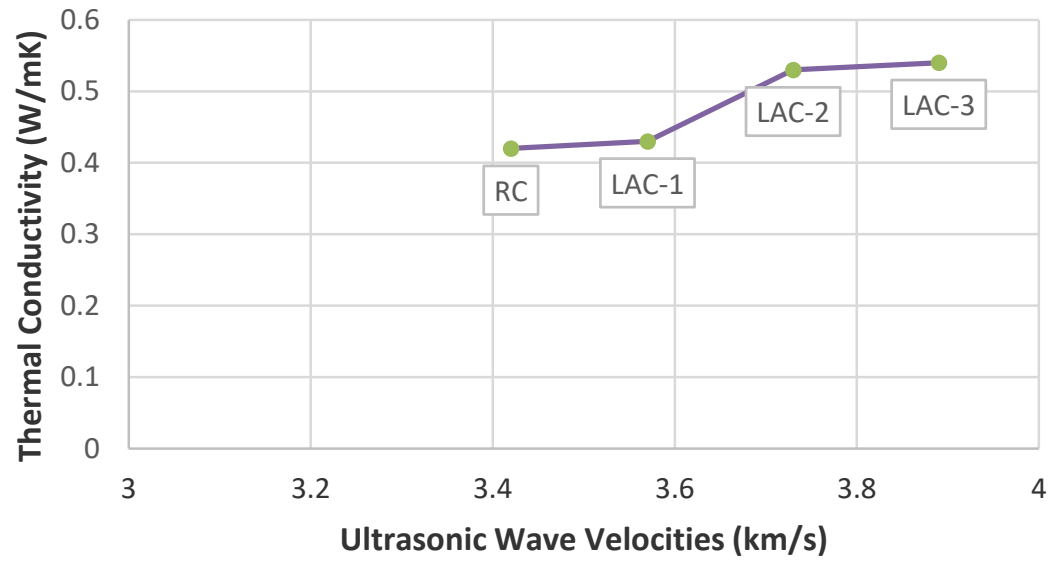

Figure 14. The thermal conductivity vs. the ultrasonic velocities of the mixes.

The results also confirm that the addition of nano-silica particles has a beneficial effect on the densification of the micro-structure accompanied by the lower porosity and a minimal increase in the thermal conductivity. The enhanced inter-particle contact configuration with the pore refinement by the addition of smaller size nano-silica can provide such modification on the thermal performance of the lightweight mixes.

Figure 15 is an X-ray CT image through a lightweight cementitious concrete core taken from the concrete slab containing 3\% nano-silica particles. It indicates that the nano-silica clusters were well interconnected which further reducing their opportunity to convey heat energy effectively through the composite and may deliver a conductivity of $0.52 \mathrm{~W} / \mathrm{m} \mathrm{K}$. 


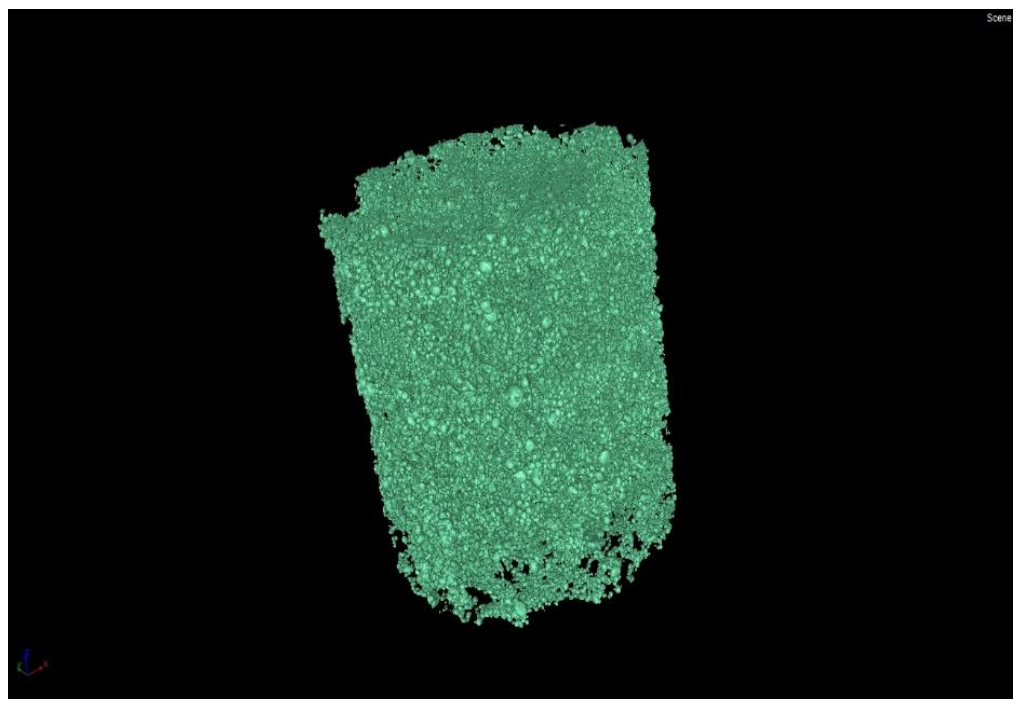

Figure 15. 3D X-ray micro-tomography views of the LAC-3 mix.

\subsection{Bond Strength}

The influence of the nano-silica modification on the bond strength of the lightweight cementitious mixes is shown in Figure 16. The addition of nano-silica to the cementitious matrix resulted in an increase in the bond strength of the lightweight concrete. Compared to the reference mix, the 28 days bond strength improvement ratios of the samples including nano-silica particles with the proportions of $1 \%, 2 \%$, and $3 \%$ by weight of cement were $4.91 \%, 51.7 \%$, and $132.1 \%$, respectively.

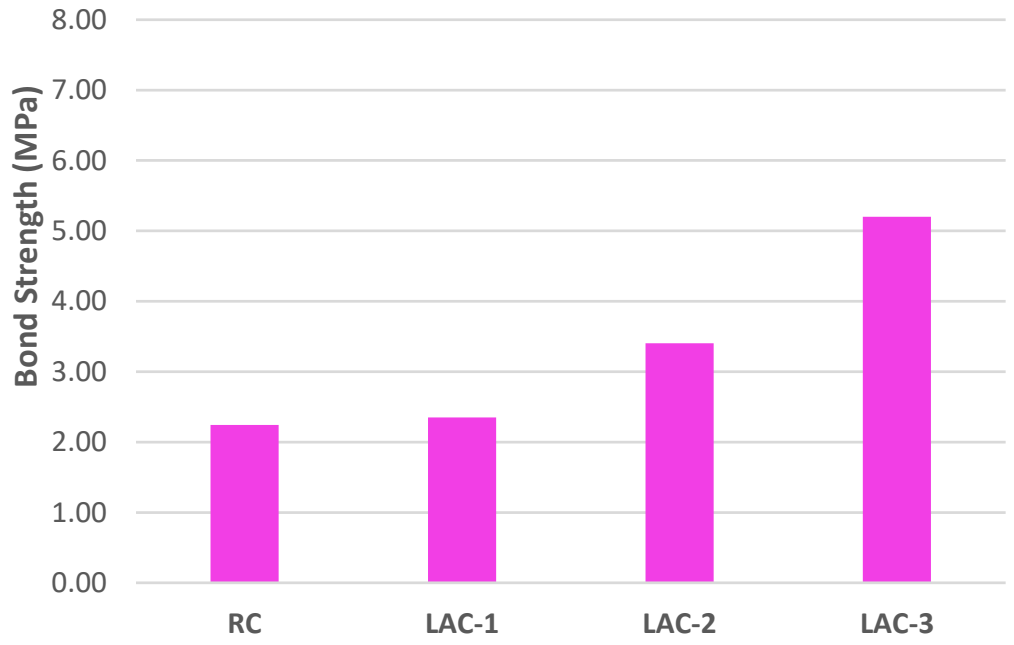

Figure 16. Bond strength test results of the mixes.

Two observations will be used to explain the significant improvement in the bond strength of the steel rebar and the nano-modified lightweight mixes. Firstly, it has been observed that the depth of the projection of the particle on the ribbed steel bars was significant which, in turn, provides a significant resistance to slippage. It was also observed that the spaces between the sand particles were not narrow due to the nano-silica densification of the interfacial transition zone of the lightweight aggregate and the surrounded cement matrix. From these observations, it can be concluded that the space that is available between the particles could accommodate a considerable amount of the nano-silica reinforced matrix to resist slippage. Moreover, it can also be plausibly presumed that in the nano-modified lightweight composites, especially with the higher dosages, at the interface between the lightweight concrete and the sand particles, the nano-silica would have reduced the contact 
between the concrete and the steel rebar. The mercury porosimetry test result presented in Section 3.3 also provides good support for this theory and indicates that the percentage of pore volume in the nano-modified lightweight mixes was significantly lower than the reference mix. This reduction in contact would contribute to a reduction in friction at the lightweight concrete and steel rebar interface resulting in an arrestor for the cracks formed in the cementitious matrix and contributed to improvement in resistance to bond failure. The highlighted factors collectively mitigated the effectiveness of the nano-modified lightweight concrete in structural applications and obliterated a significant improvement on the adherence between the ribbed steel bar and the concrete.

\section{Conclusions}

Based on the results obtained in this experimental and micro-structural study, the following conclusions can be summarized:

The increased integrity of the lightweight mix with nano-particle addition matrix improved the connected area and carrying capacity for the matrix materials that flow and deform around the lightweight aggregate against the mechanical loading.

Adding nano-silica particles into the lightweight mixes would increase the crystallinity of the mixes which, in turn, resulted in a higher micro-hardness value compared to the reference mix.

The higher fractal dimension values associated with the addition of nano-silica particles revealed that the unsaturated bonds significantly reduced the hydrophobicity and static contact angle for the nano-silica improving the bond ability between them and hydration products and producing the toughening mechanism along the crack front and voids.

Comparison of the transport properties of the lightweight concrete with nano-silica particles indicates that there is a consistently lower level of penetrability in the lightweight concrete with nano-silica over time.

Nano-silica particles could have created a more tortuous path for heat and water flow, and hence the movement of substances in the ITZ of the irregular nano-silica particles would serve to reduce the movement and minimize the transport mechanism.

The refining and densification of the cementitious matrix with the addition of nanosilica make it less favor the migration of water and chloride ions from the outside to improve the flexural and compressive strengths and the thermal performance inside, and noticeably. This, in turn, increases the potential use of this type of cementitious composites in building facades, marine environment, and bridge decks.

Based on the bond behaviour results and larger Poisson's ratio than normal weight concrete, it is possible to extend the use of the nano-modified lightweight cementitious composites in composite structural elements in high-rise buildings. The nano-modified cementitious lightweight concrete can be used in concrete-filled steel tube column. This would be particularly beneficial to decrease the affected seismic load.

Author Contributions: Conceptualization, M.A.B., and S.E.; Methodology, M.A.B., S.E., and E.G.; Formal Analysis, M.A.B., S.E., and E.G.; Investigation, M.A.B. and S.E.; Resources, E.G.; WritingOriginal Draft Preparation, M.A.B.; Writing-Review and Editing, M.A.B., S.E., and E.G.; Visualization, S.E. All authors have read and agreed to the published version of the manuscript.

Funding: The authors would like to thanks to the University Technology of Jamaica for the support. Institutional Review Board Statement: Not applicable.

Informed Consent Statement: Not applicable.

Data Availability Statement: The data presented in this study are available on request from the corresponding author.

Conflicts of Interest: The authors declare no conflict of interest. 


\section{References}

1. Abd Elrahman, M.; Chung, S.-Y.; Sikora, P.; Rucinska, T.; Stephan, D. Influence of Nanosilica on Mechanical Properties, Sorptivity, and Microstructure of Lightweight Concrete. Materials 2019, 12, 3078. [CrossRef]

2. Shannag, M.J. Characteristics of lightweight concrete containing mineral admixtures. Constr. Build. Mater. 2011, 25, 658-662. [CrossRef]

3. Ali, M.R.; Maslehuddin, M.; Shameem, M.; Barry, M.S. Thermal-resistant lightweight concrete with polyethylene beads as coarse aggregates. Constr. Build. Mater. 2018, 164, 739-749. [CrossRef]

4. Qadir, G.; Rashid, Y.; Hassan, A.; Mahmoud Vall, E.; Saleh, S.; Salim, K. Development and Mechanical Testing of PorousLightweight Geopolymer Mortar. Buildings 2021, 11, 1. [CrossRef]

5. Soon-Ching, N.; Kaw-Sai, L. Thermal conductivity of newspaper sandwiched aerated lightweight concrete panel. Energy Build. 2010, 42, 2452-2456.

6. Thomas, K.; Erika, S.; Till, V. Flexural behavior of a hybrid FRP and lightweight concrete sandwich bridge deck. Compos. Part A Appl. Sci. Manuf. 2007, 38, 879-889.

7. Siong, K.L.; Cher, S.T.; Bo, L.; Tung-Chai, L.; Uzzal, H.; Chi, S.P. Utilizing high volumes quarry wastes in the production of lightweight foamed concrete. Constr. Build. Mater. 2017, 151, 441-448.

8. Al-Jabri, K.S.; Hago, A.W.; Al-Nuaimi, A.S.; Al-Saidy, A.H. Concrete blocks for thermal insulation in hot climate. Cem. Concr. Res. 2005, 35, 1472-1479. [CrossRef]

9. Osman Ünal, T.U.; Ahmet, Y. Investigation of properties of low-strength lightweight concrete for thermal insulation. Build. Environ. 2007, 42, 584-590. [CrossRef]

10. Balendran, R.V.; Zhou, F.P.; Nadeem, A.; Leung, A.Y.T. Influence of steel fibres on strength and ductility of normal and lightweight high strength concrete. Build. Environ. 2002, 37, 1361-1367. [CrossRef]

11. Jianqing, G.; Wenjie, Z. The effects of pozzolanic powder on foam concrete pore structure and frost resistance. Constr. Build. Mater. 2019, 208, 135-143.

12. Poon, C.S.; Kou, S.C.; Lam, L. Compressive strength, chloride diffusivity and pore structure of high performance metakaolin and silica fume concrete. Constr. Build. Mater. 2006, 20, 858-865. [CrossRef]

13. Du, H. Properties of ultra-lightweight cement composites with nano-silica. Constr. Build. Mater. 2019, 199, 696-704. [CrossRef]

14. Atmaca, N.; Abbas, M.L.; Atmaca, A. Effects of nano-silica on the gas permeability, durability and mechanical properties of high-strength lightweight concrete. Constr. Build. Mater. 2017, 147, 17-26. [CrossRef]

15. Ranjbar, M.M.; Mousavi, S.Y. Strength and durability assessment of self-compacting lightweight concrete containing expanded polystyrene. Mater Struc. 2015, 48, 1001-1011. [CrossRef]

16. Vargas, P.; Marín, N.A.; Tobón, J.I. Performance and Microstructural Analysis of Lightweight Concrete Blended with Nanosilica under Sulfate Attack. Adv. Civ. Eng. 2018, 2018, 1-11. [CrossRef]

17. Yu, R.; Van Onna, D.; Spiesz, P.; Yu, Q.; Brouwers, H.; Yu, Q. Development of Ultra-Lightweight Fibre Reinforced Concrete applying expanded waste glass. J. Clean. Prod. 2016, 112, 690-701. [CrossRef]

18. Liu, R.; Xiao, H.; Liu, J.; Guo, S.; Pei, Y. Improving the microstructure of ITZ and reducing the permeability of concrete with various water/cement ratios using nano-silica. J. Mater. Sci. 2019, 54, 444-456. [CrossRef]

19. Samy, M.; El-Feky, P.; Youssef, A.; Maher El-Tair, S.; Ibrahim, M. Serag Effect of nano silica addition on enhancing the performance of cement composites reinforced with nano cellulose fibers. AIMS Mater. Sci. 2019, 6, 864-883. [CrossRef]

20. Zhang, P.; Xie, N.; Cheng, X.; Feng, L.; Hou, P.; Wu, Y. Low dosage nano-silica modification on lightweight aggregate concrete Nanomater. Nanotechnol. 2018, 8, 1-8. [CrossRef]

21. Wang, X.F.; Huang, Y.J.; Wu, G.Y.; Fang, C.; Li, D.W.; Han, N.X. Effect of nano-SiO2 on strength, shrinkage and cracking sensitivity of lightweight aggregate concrete. Constr. Build. Mater. 2018, 175, 115-125. [CrossRef]

22. Pawel, S.; Teresa, R.; Dietmar, S.; Sang-Yeop, C.; Mohamed, A. Evaluating the effects of nanosilica on the material properties of lightweight and ultra-lightweight concrete using image-based approaches. Constr. Build. Mater. 2020, 264, 1-15.

23. Erdem, S.; Gürbüz, E.; Uysal, M. Micro-mechanical analysis and X-ray computed tomography quantification of damage in concrete with industrial by-products and construction waste. J. Clean. Prod. 2018, 189, 933-940. [CrossRef]

24. Hosseini, P.; Booshehrian, A.; Delkash, M.; Ghavami, S.; Zanjani, M.K. Use of Nano-SiO2 to Improve Microstructure and Compressive Strength of Recycled Aggregate Concretes. Nanotechnol. Constr. 2009, 3, 215-221.

25. Savaş, E.; Andrew, R.D.; Nicholas, H.T. Impact load-induced micro-structural damage and micro-structure associated mechanical response of concrete made with different surface roughness and porosity aggregates. Cem. Concr. Res. 2012, 42, $291-305$.

26. Testing Hardened Concrete-Part 3: Compressive strength of test specimens, Turkish Standards Institution. TS-EN 12390-3, 29 April 2010.

27. Guo, L.P.; Sun, W.; Zheng, K.R.; Chen, H.J.; Liu, B. Study on the flexural fatigue performance and fractal mechanism of concrete with high proportions of ground granulated blast-furnace slag. Cem. Concr. Res. 2007, 37, 242-250. [CrossRef]

28. Concrete, mortar and cement-based repair materials: Chloride migration coefficient from non-steady-state migration experiments. NT BUILD 492, 21 November 1999.

29. Luo, L.; De Schutter, G. Influence of corrosion inhibitors on concrete transport properties. Mater. Struct. 2008, 41, 1571-1579. [CrossRef]

30. Testing Hardened Concrete-Part 8: Depth of penetration of water under pressure. TS-EN 12390-8, 29 April 2010. 
31. Standard test method for thermal conductivity and thermal diffusivity by modulated temperature differential scanning calorimetry. ASTM E1952, 10 April 2001.

32. ASTM E1512-01, Standard Test Methods for Testing Bond Performance of Bonded Anchors; Annual Book of ASTM Standards; ASTM International: West Conshohocken, PA, USA, 2007.

33. Erdem, S. Impact Load-Induced Microstructural Damage of Concrete Made with Unconventional Aggregates; University of Nottingham, Department of Civil Engineering: Nottingham, UK, 2012.

34. Perkins, W.G. Polymer toughness and impact resistance. Polym. Eng. Sci. 1999, 39, 2445-2460. [CrossRef]

35. Erdem, S.; Blankson, M.A. Fractal-fracture analysis and characterization of impact-fractured surfaces in different types of concrete using digital image analysis and 3D nanomap laser profilometery. Constr. Build. Mater. 2013, 40, 70-76. [CrossRef]

36. Erdem, S.; Blankson, M.A. Chloride-Ion Penetrability and Mechanical Analysis of High Strength Concrete with Copper Slag. Int. J. Eng. Res. Appl. 2014, 4, 101-113. 